\title{
Tipificación del delito de tortura en el ordenamiento jurídico chileno a la luz del Derecho Internacional de los Derechos Humanos: estado y desafíos ${ }^{1}$
}

\author{
Criminalization of torture in the Chilean legal system in the light \\ of the International Human Rights Law: status and challenges
}

\section{Felipe González Ampuero ${ }^{2}$}

fga.90@hotmail.com

Egresado de Derecho, Universidad de Chile. Ayudante ad honorem de la cátedra de Derecho Penal Internacional, Universidad de Chile.

Resumen: El presente artículo persigue determinar el estado en que se encuentra el cumplimiento de la obligación de tipificación del delito de tortura, consagrada explícitamente en tratados ratificados por el Estado chileno. Con esa finalidad, se examina en cada uno de esos instrumentos internacionales la definición del concepto de tortura y en general el contenido de la obligación de tipificación, para después analizar el nivel de adecuación del tipo penal interno respecto de las exigencias planteadas por los primeros. Por último, se analizan las diferencias entre los tratados en relación a los estándares de tipificación, con el objetivo de destacar algunas consideraciones que deberían tenerse presentes al momento de modificar el tipo interno de tortura, con el fin de cumplir las obligaciones de tipificación.

Palabras clave: tortura, obligación de tipificación, tratados, Código Penal chileno.

\begin{abstract}
The present article aims to determine the degree in which the obligation to criminalize torture, which appears explicitly in international treaties ratified by the Chilean state, has been fulfilled. With that purpose, for each one of those international instruments the definition of the concept of torture -and the content of the obligation to criminalize it-is revised, so we can then analyze how much does the domestic definition complies with the demands of those treaties. Lastly, the differences between the international treaties themselves are also analyzed in relation with the standards of criminalization, with the purpose of highlighting some considerations that should be had in mind at the time of changing the domestic definition of torture, as to fully comply with the obligation of criminalization.
\end{abstract}

Keywords: torture, obligation of criminalization, treaties, Chilean Criminal Code.

Artículo recibido el 15.09.2014 y aceptado el 21.10.2014.

El autor agradece las observaciones realizadas a un primer borrador por Elizabeth Loyola Díaz, Franklin Rojas Astorga y Benito Lea-Plaza Micheli. No obstante, cualquier error es de exclusiva responsabilidad del autor. El presente artículo corresponde a una versión revisada del trabajo enviado al IV Congreso Estudiantil de Derechos Humanos. 


\section{Introducción}

El 26 de junio de 2014, en el contexto de la conmemoración del Día Internacional de las Naciones Unidas en Apoyo de las Víctimas de la Tortura, el Ministro de Justicia declaró que en materia de derechos humanos, el Estado chileno tiene "compromisos pendientes incumplidos. Es el caso de la tortura, la que no está tipificada como delito"3. Así, el Ministro anunció que el Gobierno daría impulso a un proyecto de ley que consagre el delito de tortura en el Código Penal. ¿Puede considerarse efectivo que -según lo afirmado por el Ministro de Justicia- el delito de tortura no se encuentra tipificado en el ordenamiento jurídico nacional? Si contrariamente a lo esgrimido por la aludida autoridad estatal, el delito en cuestión sí se encontrara reconocido por la legislación penal, ¿̇e adecúa el mismo a los estándares internacionales?

Con la finalidad de responder a las interrogantes anteriores, se analizará en primer término la fuente jurídica de la obligación del Estado de tipificar el delito de tortura, así como las implicancias específicas de ese deber. En el segundo acápite se estudiará la tipificación del delito de tortura en el ordenamiento jurídico nacional, para luego determinar la adecuación del tipo interno a las definiciones consagradas en tratados de los cuales emana expresamente la obligación de tipificación, concretamente la Convención contra la Tortura y Otros Tratos o Penas Crueles, Inhumanos o Degradantes ${ }^{4}$ (en adelante "UNCAT») y la Convención Interamericana para Prevenir y Sancionar la Tortura (en adelante «CIPST») . $^{\mathrm{Al}}$ respecto, en el presente trabajo se sostiene que aun cuando se siga la idea de que el delito (autónomo) ${ }^{6}$ de tortura se encuentra tipificado en el ordenamiento jurídico nacional bajo la denominación de "tormentos o apremios ilegítimos", el mismo no satisface las exigencias planteadas por los antedichos instrumentos de derecho internacional. Por último, luego de reconocer el incumplimiento de las obligaciones de tipificación y la necesidad de impulsar una iniciativa legal que adecúe el tipo interno de tortura a los estándares internacionales, se darán a conocer ciertas

3 "Ministro de Justicia anuncia proyecto de ley para tipificar la tortura: Es una deuda pendiente" [en línea]. Emol. 26 de junio de 2014. Disponible en http://www.emol.com/noticias/nacional/2014/06/26/667188/ ministro-de-justicia-anuncia-proyecto-de-ley-para-tipificar-la-tortura-es-una-deuda-pendiente.html [consulta: 6 de agosto de 2014].

4 Adoptada el 10 de diciembre de 1984, con entrada en vigor el 26 de junio de 1987. Fue ratificada por Chile el 30 de septiembre de 1988, promulgada por el Decreto No 808, de 7 de octubre de 1988 y publicada en el Diario Oficial el 26 de noviembre de 1988.

5 Adoptada el 12 de septiembre de 1985, con entrada en vigor el 28 de febrero de 1987. Fue ratificada por Chile el 30 de septiembre de 1988, promulgada por el Decreto No 809, de 7 de octubre de 1987 y publicada en el Diario Oficial el 26 de noviembre de 1988.

6 Como se indicará más adelante, es necesario distinguir la tortura como delito autónomo de la tortura como crimen de lesa humanidad o crimen de guerra. 
consideraciones que debieran tenerse en cuenta al momento de legislar en la materia. Específicamente, desde el punto de vista del cumplimiento de las referidas obligaciones y al margen de las críticas que pudieran formularse a las definiciones contempladas en los tratados, se señalará cuál de esas definiciones debiera favorecerse y por qué.

\section{Origen de la obligación de tipificar el delito de tortura}

Si bien resulta acertada la idea consistente en que la obligación de tipificar el delito de tortura en los ordenamientos jurídicos nacionales "deriva en general del deber de garantía del Estado, así como del carácter de jus cogens de la prohibición de la misma y de las obligaciones erga omnes que emanan de ésta"7, en el caso del Estado chileno dicho deber jurídico se encuentra explícitamente consagrado ${ }^{8}$ en la UNCAT y en la CIPST 9 .

\section{a) Convención contra la Tortura y Otros Tratos o Penas Crueles, Inhumanos o Degra- dantes (UNCAT)}

La UNCAT, en su artículo 1.1, define el concepto de tortura como "todo acto por el cual se inflija intencionadamente a una persona dolores o sufrimientos graves, ya sean físicos o mentales, con el fin de obtener de ella o de un tercero información o una confe-

7 Andreu-Guzmán, F. «La prohibición de la tortura y el derecho internacional» [en línea]. En: Memorias del Seminario sobre los instrumentos nacionales e internacionales para prevenir, investigar y sancionar la tortura. Programa de Cooperación sobre Derechos Humanos México-Comisión Europea. México D.F., 2004. Disponible en: <http://biblio.juridicas.unam.mx/libros/5/2472/7.pdf> [fecha de consulta: 7 de agosto de 2014], p. 83. Para un análisis sobre el reconocimiento jurisprudencial de la prohibición de la tortura como norma de ius cogens y sus implicancias, véase AguiLAR, G. "El reconocimiento jurisprudencial de la tortura y de la desaparición forzada de personas como normas imperativas de derecho internacional público». Ius et Praxis, vol. 12, n 1,2006 , pp. 117-154.

8 La obligación de tipificar el delito de tortura también puede desprenderse de los artículos 2.2 y 7 del Pacto Internacional de Derechos Civiles y Políticos y del artículo 2 de la Convención Americana de Derechos Humanos. Asimismo, la aludida obligación puede colegirse de los artículos 4 y 37 de la Convención de los Derechos del Niño; 4 y 15 de la Convención sobre los Derechos de las Personas con Discapacidad; 10 y 84 de la Convención Internacional sobre la Protección de los Derechos de todos los Trabajadores Migratorios y de sus Familiares y 2, 4 y 7 de la Convención Interamericana para Prevenir, Sancionar y Erradicar la Violencia contra la Mujer. Empero, a diferencia de la UNCAT y la CIPST, en los tratados antedichos no se consagra de manera explícita la obligación de tipificar la tortura ni se estatuye una definición de la misma. Son estos dos últimos factores los que sólo permiten tener en consideración la UNCAT y la CIPST en el presente trabajo, ya que la existencia de una definición en dichos tratados permite confrontarlas con el tipo penal que pueda encontrarse regulado en el derecho interno, determinándose así si se cumple o no la obligación de tipificación.

9 Para un análisis de la obligación de tipificación de la tortura en la UNCAT y en la CIPST, véase AsociaCióN Para la Prevención De la Tortura (Apt) y Centro Por la Justicia Y El Derecho Internacional (CEJIL). "La tortura en el derecho internacional, guía de jurisprudencia” [en línea]. Disponible en: <http:// www.apt.ch/content/files_res/JurisprudenceGuideSpanish.pdf> [consulta: 7 de agosto de 2014]. 
sión, de castigarla por un acto que haya cometido, o se sospeche que ha cometido, o de intimidar o coaccionar a esa persona o a otras, o por cualquier razón basada en cualquier tipo de discriminación, cuando dichos dolores o sufrimientos sean infligidos por un funcionario público u otra persona en el ejercicio de funciones públicas, a instigación suya, o con su consentimiento o aquiescencia. No se considerarán torturas los dolores o sufrimientos que sean consecuencia únicamente de sanciones legítimas, o que sean inherentes o incidentales a éstas".

A su vez, el artículo 4 consagra expresamente la obligación de tipificación ${ }^{10}$ para los Estados partes del tratado ${ }^{11}$ :

“1. Todo Estado Parte velará por que todos los actos de tortura constituyan delitos conforme a su legislación penal. Lo mismo se aplicará a toda tentativa de cometer tortura y a todo acto de cualquier persona que constituya complicidad o participación en la tortura.

2. Todo Estado Parte castigará esos delitos con penas adecuadas en las que se tenga en cuenta su gravedad".

En otras palabras, según el mencionado artículo 4 de la UNCAT, los Estados partes no sólo se encuentran obligados a consagrar como ilícitos penales aquellas conductas que sean constitutivas de tortura, sino que además los Estados deben castigar, en sus legislaciones penales, la tentativa y aquellos actos que impliquen complicidad o participación en el acto de tortura. A pesar de la ambigüedad de los vocablos "complicidad" y "participación", se ha señalado que tales expresiones deben entenderse en un sentido amplio, de manera tal que se incluirían en ellas formas de responsabilidad como el encubrimiento, así como aquellas contempladas por el artículo 1 de la UNCAT ${ }^{12}$.

Ahora bien, ¿es compatible con la UNCAT cualquier forma de tipificación de la tortura

10 Para un extenso análisis sobre las obligaciones de tipificación derivadas de normas internacionales, véase Bascuñán, A. «Derechos Fundamentales y Derecho Penal». Revista de Estudios de la Justicia, no 9, 2007, pp. 59-70.

11 En la UNCAT, la obligación de tipificación establecida por el artículo $4^{\circ}$ debe ser entendida como una manifestación del deber general consagrado en el artículo $2^{\circ}$, que obliga al Estado a tomar medidas eficaces (legislativas, administrativas, judiciales o de otro tipo) para impedir los actos de tortura en su territorio.

12 Nowak, M. y Mcarthur, E. The United nations Convention against Torture: A Commentary, Oxford University Press, Oxford, 2008, pp. 232-233 apud Tully, S. «Australians Torturing Australians Overseas: The Risk of Complicity» [en línea], p. 4, n. 35. Disponible en: <http://papers.ssrn.com/sol3/papers. cfm?abstract_id=1551184> [consulta: 9 de septiembre de 2014]. La comprensión amplia de la complicidad y la participación se basa principalmente en los trabajos preparatorios de la UNCAT y en la jurisprudencia del CAT. Véase, también, Burgers, J. y Danelius, H. The United Nations Convention against Torture: A Handbook on the Convention against Torture and Other Cruel, Inhuman or Degrading Treatment or Punishment, Martinus Nijhoff, The Hague, 1988, pp. 129-130. 
a nivel interno, o el tipo más bien debe cumplir ciertas exigencias? Sin duda alguna, la segunda alternativa es la que debe ser tenida por correcta. La tipificación del crimen de tortura en el ordenamiento nacional debe guardar conformidad con la definición establecida por el artículo 1.1 de la UNCAT, aspecto que ha sido destacado por el Comité contra la Tortura (en adelante "CAT»), órgano encargado de vigilar el cumplimiento de la Convención. En este sentido, el CAT ha expresado que "para cumplir cabalmente con [las] obligaciones dimanantes de la Convención, [el Estado Parte] debe adoptar una definición de la tortura estrictamente conforme al artículo 1 "13. Sin embargo, la obligación de tipificación en la UNCAT no demandaría a los Estados partes la reproducción textual de la definición proporcionada por el artículo 1.1, sino que el concepto del delito de tortura que se consagre en la legislación interna debe abarcar a lo menos los elementos proporcionados por la disposición en cuestión ${ }^{14}$. El CAT ha señalado que el artículo 4 exige a los Estados partes que "proceda[n] a incorporar en su derecho interno el delito de tortura y adopte[n] una definición de tortura que abarque todos los elementos contenidos en el artículo 1 de la Convención" 15 (cursiva nuestra). Por consiguiente, los Estados partes, al tipificar el delito de tortura, pueden optar por contemplar una definición más amplia que la establecida por el artículo 1.1 de la UNCAT, posibilidad que se encuentra en armonía con el mismo cuerpo normativo toda vez que su artículo 1.2 dispone que: "El presente artículo se entenderá sin perjuicio de cualquier instrumento internacional o legislación nacional que contenga o pueda contener disposiciones de mayor alcance" 16 .

Por otro lado, como parte de la obligación en comento, el párrafo 2 del artículo 4 obliga a los Estados partes a sancionar el delito de tortura con penas acordes a la gravedad del crimen. A pesar que el CAT no se ha pronunciado terminantemente sobre el rango específico de penas que debiese comportar el delito de tortura, se ha sostenido que la sanción aplicable a dicho ilícito debería ser cercana a la pena asignada a los delitos considerados más graves en el ordenamiento interno ${ }^{17}$. Más concretamente, se ha propuesto

13 Comité Contra la Tortura. “Observaciones finales del Comité contra la Tortura: Armenia”. A/56/44, 17 de noviembre de 2000 , párr. 39.

14 Ingelse, C. The UN Committee against Torture: An assessment. Kluwer Law International, The Netherlands, 2001, p. 340. En la doctrina se han diferenciado los "deberes moderados de tipificación", de los cuales emana una exigencia de congruencia -no de transcripción- entre el texto doméstico y el texto del instrumento internacional, de los "deberes extremos de tipificación", de los cuales deriva la exigencia de transcribir los términos y expresiones del texto del instrumento internacional. En este sentido, la obligación de tipificación derivada de la UNCAT correspondería a un "deber moderado de tipificación". Véase BAsCuñán, A., op. cit., pp. 61 y ss.

15 Comité Contra la Tortura. “Observaciones finales del Comité contra la Tortura: Italia”. CAT/C/ITA/ CO/4, 18 de mayo de 2007, párr. 5.

16 La cursiva es nuestra.

17 BURGERS, J. y DANELIUS, H., op. cit., p. 129. 
en doctrina, en base a las opiniones individuales de los miembros del CAT, que una pena adecuada oscilaría entre los 6 y 20 años de prisión ${ }^{18}$.

b) Convención Interamericana para Prevenir y Sancionar la Tortura (CIPST)

La CIPST, en su artículo 2, define tortura como "todo acto realizado intencionalmente por el cual se inflijan a una persona penas o sufrimientos físicos o mentales, con fines de investigación criminal, como medio intimidatorio, como castigo personal, como medida preventiva, como pena o con cualquier otro fin. Se entenderá también como tortura la aplicación sobre una persona de métodos tendientes a anular la personalidad de la víctima o a disminuir su capacidad física o mental, aunque no causen dolor físico o angustia psíquica. No estarán comprendidos en el concepto de tortura las penas o sufrimientos físicos o mentales que sean únicamente consecuencia de medidas legales o inherentes a éstas, siempre que no incluyan la realización de los actos o la aplicación de los métodos a que se refiere el presente artículo".

Este último precepto debe ser complementado con el artículo 3 del mismo tratado, el cual indica quiénes deben ser considerados como responsables del ilícito en cuestión, a saber: "(a) los empleados o funcionarios públicos que actuando en ese carácter ordenen, instiguen, induzcan a su comisión, lo cometan directamente o que, pudiendo impedirlo, no lo hagan" y "(b) las personas que, a instigación de los funcionarios o empleados públicos a que se refiere el inciso a., ordenen, instiguen o induzcan a su comisión, lo cometan directamente o sean cómplices".

Enseguida, la obligación de tipificación en la CIPST se encuentra expresamente contemplada por los incisos $1^{\circ}$ y $2^{\circ}$ del artículo $6^{19}$ :

"De conformidad con lo dispuesto en el artículo 1, los Estados partes tomarán medidas efectivas para prevenir y sancionar la tortura en el ámbito de su jurisdicción.

Los Estados partes se asegurarán de que todos los actos de tortura y los intentos de cometer tales actos constituyan delitos conforme a su derecho penal, estableciendo para castigarlos sanciones severas que tengan en cuenta su gravedad".

$\mathrm{Al}$ igual que en la UNCAT, no cualquier consagración legal del delito de tortura es apta para satisfacer la obligación de tipificación derivada de la CIPST. En este sentido, el

18 Ingelse, C., op. cit., p. 342. Cabe apuntar que el rango propuesto considera los casos de tortura con resultado de muerte.

19 Al igual que en la UNCAT, la obligación de tipificación derivada de la CIPST correspondería a un "deber moderado de tipificación". 
tipo establecido por el ordenamiento jurídico interno de los Estados partes debe reunir a lo menos los elementos que componen la definición entregada por los artículos 2 y 3 de dicho tratado. Esta última exigencia se encuentra estatuida por el artículo 1 de la CIPST, el que demanda a los Estados partes sancionar y prevenir la tortura "en los términos de la Convención”. A pesar que la Corte Interamericana de Derechos Humanos (en adelante la Corte IDH) no se ha pronunciado sobre la aludida obligación de forma tan categórica como el CAT, puede inferirse que la misma estima que la definición de la CIPST representa, en los términos de la Corte IDH, un "estándar mínimo" que el tipo interno debe cumplir. Precisamente, la Corte IDH declaró en el caso Goiburú y otros vs. Paraguay en relación a los delitos de tortura y desaparición forzada consagrados en el Código Penal paraguayo que:

"[U]n análisis de los mismos [tipos penales] permite observar que el Estado las tipificó [tortura y desaparición forzada] de manera menos comprehensiva que la normativa internacional aplicable. El Derecho Internacional establece un estándar mínimo acerca de una correcta tipificación de esta clase de conductas y los elementos mínimos que la misma debe observar, en el entendido de que la persecución penal es una vía fundamental para prevenir futuras violaciones de derechos humanos. Es decir, que los Estados pueden adoptar una mayor severidad en el tipo específico para efectos de una mejor persecución penal de esos delitos, en función de lo que consideren una mayor o mejor tutela de los bienes jurídicos protegidos, a condición de que al hacerlo no vulneren esas otras normas a las que están obligados"20.

A mayor abundamiento, la Corte IDH en el caso Heliodoro Portugal vs. Panamá determinó que el Estado incumplió la obligación de "modificar su legislación interna con el propósito de tipificar el delito de tortura" ${ }^{21}$. Específicamente, el tribunal consideró que la figura penal de la tortura regulada en el Código Penal nacional no incluía los supuestos de responsabilidad de "personas que a instigación de los funcionarios o empleados públicos [...] ordenen, instiguen o induzcan a su comisión, lo cometan directamente o sean cómplices", todos reconocidos en el artículo 3.b) de la $\operatorname{CIPST}^{22}$.

Por último, al igual que el CAT, la CIPST exige en el inciso $2^{\circ}$ del artículo 6 que los actos calificados como tortura (incluyendo la tentativa) deben ser castigados con sanciones acordes a la gravedad del delito.

20 Corte IDH. Caso Goiburú y otros vs. Paraguay. Fondo, reparaciones y costas. Sentencia de 22 de septiembre de 2006. Serie C No. 153, párr. 92.

21 Corte IDH. Caso Heliodoro Portugal vs. Panamá. Excepciones preliminares, fondo, reparaciones y costas. Sentencia de 12 de agosto de 2008. Serie C No. 186, párr. 216.

22 Idem, párr. 215. 


\section{Tipificación de la tortura en el ordenamiento jurídico chileno}

Al hablar sobre la tipificación del delito de tortura en el ordenamiento jurídico chileno, se hace necesario efectuar una distinción que dice relación con las circunstancias en que son cometidos los actos que son susceptibles de ser calificados como tortura. A este respecto, se ha sostenido que "[l] os actos constitutivos de tortura, calificados como crimen bajo el derecho internacional, pueden ser incriminados, según las circunstancias, como tortura per se, crimen de lesa humanidad, crimen de guerra o genocidio" 23 . Por consiguiente, para los efectos de determinar el estado en que se encuentra la tipificación del ilícito referido, se hace preciso diferenciar la tortura como crimen de lesa humanidad y crimen de guerra, de la tortura como delito autónomo.

a) Tipificación de la tortura como crimen de lesa humanidad y crimen de guerra

El 18 de julio de 2009 fue publicada en el Diario Oficial la Ley $N^{\circ}$ 20.357, que "tipifica crímenes de lesa humanidad y genocidio y crímenes y delitos de guerra". Esta última norma tiene como objetivo implementar en el ordenamiento jurídico interno, los crímenes contra el derecho internacional reconocidos en el Estatuto de la Corte Penal Internacional, otorgando así a los tribunales nacionales competencia sobre los mismos. En su artículo $7 \mathrm{~N}^{\circ} 1$, la Ley $\mathrm{N}^{\circ} 20.357$ tipifica el delito de tortura como crimen de lesa humanidad, mientras que el artículo 21 tipifica como crímenes de guerra los actos del artículo 7 , incluyendo la tortura. El artículo 7 No 1 prescribe:

"Será castigado con la pena de presidio mayor en su grado mínimo a medio, el que, concurriendo las circunstancias descritas en el artículo $1^{\circ}$ :

$1^{\circ}$. Torturare a otro que se encuentre bajo su custodia o control, infligiéndole graves dolores o sufrimientos físicos o mentales. Sin embargo, no se entenderá por tortura el dolor o los sufrimientos que deriven únicamente de sanciones lícitas o que sean consecuencia normal o fortuita de ellas.

Si además de la realización de las conductas descritas en este numeral se causare alguna de las lesiones previstas en el artículo 397 del Código Penal o la muerte de la persona bajo custodia o control, siempre que el resultado fuere imputable a negligencia o imprudencia del hechor, la pena será de presidio mayor en su grado medio a máximo" 24 .

23 Andreu-Guzmán, F., op. cit., p. 71.

24 Congreso Nacional de Chile. 2009. Ley N²0.357, que tipifica crímenes de lesa humanidad y genocidio y crímenes y delitos de guerra. 
Cabe destacar que los tipos de tortura como crimen de lesa humanidad y crimen de guerra regulados por la ley No 20.357, en los artículos indicados, se encuentran consagrados en los mismos términos del Estatuto de Roma. Es más, en el tipo interno se ańaden agravantes establecidas por el inciso $2^{\circ}$ del artículo $7^{25}$. Con todo, debe puntualizarse que el Estatuto de Roma no contempla una obligación de implementar los crímenes de competencia de la Corte Penal Internaciona ${ }^{26}$. ¿Deriva, entonces, de la UNCAT y la CIPST la obligación de tipificar la tortura como crimen de lesa humanidad y crimen de guerra? No parece haber en doctrina un abundante tratamiento de la cuestión, y -por exceder el objeto del presente estudio - no se esbozará en este trabajo una respuesta. Sin embargo, para los efectos de constatar el cumplimiento de la obligación de tipificación, específicamente para el caso chileno la respuesta a la interrogante anterior carece de importancia. En consecuencia, si entendiésemos que la regulación de la tortura como crimen de lesa humanidad y crimen de guerra forma parte de la obligación de tipificación emanada de la UNCAT y de la CIPST, entonces la obligación no necesariamente se encontraría completamente cumplida, toda vez que restaría constatar si está satisfactoriamente tipificada la tortura como delito autónomo. Luego, si en cambio asumiéramos que la regulación de la tortura como crimen de lesa humanidad y crimen de guerra no forma parte de la obligación de tipificación, entonces los artículos 7 No 1 y 21 de la ley No 20.357 serían jurídicamente irrelevantes para las obligaciones de tipificación de la UNCAT y la CIPST. En otras palabras, para los efectos de este trabajo, la respuesta carece de importancia pues en ambos casos la obligación podría no encontrarse íntegramente satisfecha, dependiendo de la tipificación de la tortura como delito autónomo y de su adecuación a las definiciones de los tratados.

b) Tipificación de la tortura como delito autónomo

La ley No 19.567 introdujo un conjunto de modificaciones al Código de Procedimiento Penal y al Código Penal, con el objetivo de dar cumplimiento al mandato constitucional de "adecuar la legislación interna [a los tratados ratificados por Chile] a fin de garantizar la vigencia de los Derechos Humanos" 27 en distintas materias, entre ellas "la protección contra la tortura" ${ }^{28}$. La principal novedad aportada por la ley en cuestión, consistió en la modificación del artículo 150 del Código Penal ${ }^{29}$ y la inserción de los artículos 150 A y 150 B. Estas dos últimas disposiciones estatuyen el delito de tormentos o

25 CÁrdenas, C. «La implementación de los crímenes de competencia de la Corte Penal Internacional en la Ley no 20.357». Revista de Derecho, vol. 23, n², 2010, p. 29.

26 CÁrdenas, C. «Los crímenes del Estatuto de la Corte Penal Internacional en el derecho chileno, necesidad de una implementación». Política Criminal, n², 2006, pp. 5-6.

27 Biblioteca del Congreso Nacional. Historia de la ley No 19.567, de 1 de julio de 1998. Disponible en: <http://www.bcn.cl>, p. 4.

28 Ibidem.

29 Congreso Nacional de Chile. 1874. Código Penal. 
apremios ilegítimos -que ya se encontraba sancionado en el antiguo artículo $150^{30} \mathrm{sin}$ una descripción detallada-, ilícito que de acuerdo a la doctrina ${ }^{31}$ y al Estado ${ }^{32}$ ( $\sin$ perjuicio de la declaración del Ministro de Justicia) correspondería al delito de tortura.

El artículo 150 A, entonces, castigaría los actos de tortura en que tenga participación un funcionario público ${ }^{33}$ :

"El empleado público que aplicare a una persona privada de libertad tormentos o apremios ilegítimos, físicos o mentales, u ordenare o consintiere su aplicación, será castigado con las penas de presidio o reclusión menor en sus grados medio a máximo y la accesoria correspondiente.

Las mismas penas, disminuidas en un grado, se aplicarán al empleado público que, conociendo la ocurrencia de las conductas tipificadas en el inciso precedente, no las impidiere o hiciere cesar, teniendo la facultad o autoridad necesaria para ello.

Si mediante alguna de las conductas descritas en el inciso primero el empleado público compeliere al ofendido o a un tercero a efectuar una confesión, a prestar algún tipo de declaración o a entregar cualquier información, la pena será de presidio o reclusión menor en su grado máximo a presidio o reclusión mayor en su grado mínimo y la accesoria correspondiente.

Si de la realización de las conductas descritas en este artículo resultare alguna de las lesiones previstas en el artículo 397 o la muerte de la persona privada de libertad, siempre que el resultado fuere imputable a negligencia o imprudencia del empleado público, la pena será de presidio o reclusión mayor en su grado mínimo a medio y de inhabilitación absoluta perpetua".

30 El artículo 150 en su versión original estipulaba:

"Sufrirán las penas de presidio o reclusión menores y suspensión en cualesquiera de sus grados:

1. Los que decretaren o prolongaren indebidamente la incomunicación de un procesado, le aplicaren tormentos o usaren contra él de un rigor innecesario. Si de la aplicación de los tormentos o del rigor innecesariamente empleado resultaren lesiones o la muerte del paciente, se aplicarán al responsable las penas señaladas a estos delitos en sus grados máximos.

2. Los que arbitrariamente hicieren arrestar o detener en otros lugares que los designados por la ley".

31 Véanse Garrido Montt, M. Derecho Penal. Parte Especial, Tomo III. Editorial Jurídica de Chile, Santiago, 2010, pp. 407-412 y Politoff, S./Matus J. y Ramírez M. Lecciones de Derecho Penal Chileno. Parte Especial. Editorial Jurídica de Chile, Santiago, 2005, pp. 217-221.

32 Comité Contra la Tortura. "Respuestas por escrito del gobierno de Chile a la lista de cuestiones que deben abordarse al examinar el quinto informe periódico de Chile". CAT/C/CHL/Q/5/Add.1, 30 de marzo de 2009, párr. 1.

33 El concepto de funcionario público debe ser entendido según lo preceptuado por el artículo 260 del Código Penal, es decir, "todo el que desempeñe un cargo o función pública, sea en la Administración Central o en instituciones o empresas semifiscales, municipales, autónomas u organismos creados por el Estado o dependientes de él, aunque no sean del nombramiento del Jefe de la República ni reciban sueldos del Estado. No obstará a esta calificación el que el cargo sea de elección popular". 
A su vez, el artículo 150 B castigaría la participación de privados en la comisión de un hecho subsumible en el artículo 150 A. Específicamente, el artículo 150 B no castiga la participación autónoma de privados en un hecho constitutivo de tortura, sino que sanciona la participación de aquéllos en un hecho constitutivo de tortura en que se encuentre involucrado un funcionario público ${ }^{34}$ :

"Al que, sin revestir la calidad de empleado público, participare en la comisión de los delitos sancionados en los dos artículos precedentes, se le impondrán las siguientes penas:

$1^{\circ}$. Presidio o reclusión menor en su grado mínimo a medio, en los casos de los artículos 150 y $150 \mathrm{~A}$, inciso primero;

2o. Presidio o reclusión menor en su grado medio a máximo, en el caso del inciso segundo del artículo $150 \mathrm{~A}, \mathrm{y}$

$3^{\circ}$. Presidio o reclusión menor en su grado máximo a presidio o reclusión mayor en su grado mínimo, si se tratare de la figura del último inciso del artículo 150 A.

En todos estos casos se aplicarán, además, las penas accesorias que correspondan".

Así las cosas, si el delito de tortura se encuentra reconocido en los artículos $150 \mathrm{~A}$ y 150 B del Código Penal, deviene necesario determinar si el mismo se adecúa o no a las definiciones contempladas en la UNCAT y en la CIPST.

\section{b.1) Adecuación del tipo interno a la UNCAT}

El 23 de junio de 2009, el CAT dio a conocer sus observaciones finales sobre el informe periódico presentado por Chile al mismo. En ellas, el Comité manifestó que "la definición de tortura en el Estado parte sigue sin estar plenamente en consonancia con lo dispuesto en el artículo 1 de la Convención" 35 , exhortando al Estado a "adoptar las

Véanse Garrido Montt, M., loc. cit., y Politoff/Matus/Ramírez, loc. cit.

35 Comité Contra la Tortura. "Observaciones finales del Comité contra la Tortura: Chile”. CAT/C/CHL/ CO/5, 23 de junio de 2009, párr. 10. El Comité señaló en el mismo párrafo que "el Código Penal no contempla todos los actos punibles contenidos en la Convención, tales como la tentativa”, afirmación que en nuestra opinión debe ser tenida como incorrecta. En efecto, tanto la tentativa como las formas de complicidad y de participación a las que hace alusión el artículo 4 de la UNCAT (que incluirían a su vez las formas de responsabilidad englobadas por la definición del artículo 1), se encontrarían cubiertas por las disposiciones de la parte general del Código Penal chileno. En este sentido, la aplicación de normas generales de responsabilidad para sancionar actos como la tentativa de tortura, no sería contraria a la UNCAT, instrumento que no exigiría una sanción autónoma de las distintas formas de responsabilidad. Sobre este 
medidas necesarias para asegurar que todos los actos de tortura aludidos en los artículos 1 y 4 de la Convención sean considerados delitos en su legislación penal interna"36. Además, el Comité señaló como motivos de preocupación la inexistencia de penas apropia$\mathrm{das}^{37}$. Dicho lo anterior, centrando nuestro análisis exclusivamente en la descripción ${ }^{38}$ del delito autónomo de tortura como delito autónomo, ¿cuáles son las diferencias de los artículos 150 A y 150 B del Código Penal con el artículo 1 de la UNCAT?

- Una primera diferencia del tipo nacional con la definición de la UNCAT, advertida por el Comité contra la Tortura, es que el artículo $150 \mathrm{~A}$ limita las potenciales víctimas de tortura a personas privadas de libertad ${ }^{39}$-legal o ilegalmente de acuerdo al Estado de Chile ${ }^{40}$-, mientras que en el artículo 1 del UNCAT cualquier persona puede ser víctima de tortura sin necesidad de encontrarse privada de libertad ${ }^{41}$.

- Mientras la UNCAT utiliza el vocablo tortura, los artículos 150 A y 150 B emplean la expresión "tormentos o apremios ilegítimos" (el segundo artículo por referencia al primero).

- El artículo 150 A no exige que los tormentos o apremios ilegítimos sean graves, a diferencia del artículo 1 de la UNCAT que sí lo exige.

- En el artículo 150 A no sería obligatorio que la conducta tenga un propósito

último punto, véase Messineo, F. «Extraordinary Renditions’ and State Obligations to Criminalize and Prosecute Torture in the Light of the Abu Omar Case in Italy». Journal of International Criminal Justice, vol. 7, no 5, 2009, pp. 1028-1029.

36 Comité Contra la Tortura, loc. cit.

37 Ibidem.

38 No se analizará en el presente trabajo la suficiencia o insuficiencia de las penas aplicables a los delitos regulados por los artículos 150 A y B del Código Penal, toda vez que -como indicamos anteriormente- el CAT no ha precisado qué rango de penas serían aceptables a la luz del artículo 4 de la UNCAT.

39 Comité Contra la Tortura. Lista de cuestiones que han de abordarse al examinar el quinto informe periódico de Chile. CAT/C/CHL/Q/5, 12 de febrero de 2009, párr. 1.

40 Comité Contra La Tortura. Respuestas por escrito del gobierno de Chile a la lista de cuestiones que deben abordarse al examinar el quinto informe periódico de Chile. CAT/C/CHL/Q/5/Add.1, 30 de marzo de 2009, párrs. 2-3.

41 Aunque puede decirse que las personas detenidas se encuentran en una situación especialmente vulnerable que las convierte en potenciales víctimas de tortura, se ha estimado que podrían llegar a configurarse actos de tortura sin que exista una detención. Por ejemplo, actos de violencia sexual y mutilación genital femenina perpetrados por privados en el ámbito doméstico y tolerados por el Estado pueden ser subsumidos en el artículo 1 de la UNCAT. Incluso la existencia de algunas normas, como por ejemplo leyes de aborto extremadamente restrictivas, pueden llegar a constituir un acto que sea calificado como tortura. Véase OfFice OF THe High COMmissioner for Human Rights. Interpretation of torture in the light of the practice and jurisprudence of international bodies [en línea], 2011, 30 pp. Disponible en: <http://www.ohchr.org/ Documents/Issues/Torture/UNVFVT/Interpretation_torture_2011_EN.pdf> [consulta: 8 de agosto de 2014]. 
específico, a diferencia del artículo 1 de la UNCAT ${ }^{42}$. Es más, en el tipo interno la concurrencia de ciertos propósitos sólo permitiría determinar si se agrava o no la pena ${ }^{43}$.

De las diferencias indicadas, las dos últimas no deben ser valoradas negativamente por cuanto posibilitan que el tipo interno abarque casos que no quedarían comprendidos en la definición de la UNCAT. No obstante, la primera diferencia referida a limitar las víctimas a personas que se encuentren privadas de libertad, conlleva a que el tipo nacional de la tortura no abarque casos que sí se encontrarían cubiertos por la definición del artículo 1 de la UNCAT ${ }^{44}$.

Por último, si bien la diferencia de denominación -esto es, entender tormentos o apremios ilegítimos como tortura- no restringe el alcance de la definición interna en relación a la del artículo 1 de la UNCAT, y por ende no tendría consecuencias prácticas al momento de perseguir las conductas constitutivas de tortura, resulta fundamental utilizar la terminología apropiada. Por ejemplo, se ha dicho que la utilización de la expresión tormentos o apremios ilegítimos puede "prestarse a una interpretación equivocada y ambigua" ${ }^{45}$. Por otro lado, al tratarse de un delito gravísimo cuya prohibición es absoluta, se hace necesario que los actos que sean constitutivos de tortura sean llamados como tales y no según otra denominación. $\mathrm{Al}$ respecto, si frente a un hecho constitutivo de tortura, se utiliza un vocablo distinto (como lo es la expresión "tormentos o apremios ilegítimos") para referirse a él, podría ocurrir que ese hecho no genere el impacto social que debería producirse de acuerdo a la gravedad del crimen en cuestión. Si bien la expresión "tormentos o apremios ilegítimos" puede llegar a ser vinculada por un lego al concepto de tortura (asociación que no es necesaria), creemos que es mayor el impacto social o rechazo que produce en una persona el enterarse de la ocurrencia de un hecho

42 De acuerdo a parte de la doctrina nacional, el uso de las expresiones "tormento" y "apremios ilegítimos" presupone la exigencia de una intencionalidad (dolo directo), razonamiento que a nuestro juicio sería correcto. Sin embargo, a partir de esas expresiones no puede deducirse -como equivocadamente lo ha hecho parte de la doctrina- que el tipo exija la concurrencia de un propósito especial distinto al de infligir los tormentos o apremios ilegítimos, ni tampoco puede deducirse que esos propósitos sean -vía interpretaciónlos que describe la UNCAT. Para la presuposición de la exigencia de un dolo directo, véase GARRIDo Montt, M., loc. cit. Para la deducción de la exigencia de un propósito especial, ver Politoff/Matus/ RAmírez, loc. cit.

43 El artículo 150 A sanciona con una pena agravada la comisión de la tortura, con el fin de compeler a la víctima o a un tercero a realizar una confesión o declaración, o a entregar alguna información.

44 No sólo el Comité contra la Tortura ha constatado esta insuficiencia, sino que la misma también fue identificada en el Examen Periódico Universal. Véase Consejo DE DEREChos humanos. "Informe del Grupo de Trabajo sobre el Examen Periódico Universal: Chile”. A/HRC/26/5, 2 de abril de 2014, párr. 121.26, 121.74, 121.75.

45 Instituto Nacional De Derechos Humanos. Informe Anual 2013: Situación de los Derechos Humanos en Chile [en línea], p. 80. Disponible en: <http://bibliotecadigital.indh.cl/bitstream/handle/123456789/605/ INFORME\%20ANUAL\%202013.pdf?sequence=4> [consulta: 10 de agosto de 2014] 
constitutivo de tortura. Finalmente, es esencial emplear la denominación correcta ya que ello permite que la sociedad comprenda que la tortura no es un ilícito vinculado exclusivamente a actos cometidos por agentes estatales en regímenes dictatoriales, sino que se trata de una realidad presente incluso en gobiernos democráticos ${ }^{46}$.

En suma, la pretendida consagración penal de la tortura, en los artículos 150 A y B del Código Penal, no cubre todos los casos abarcados por la definición entregada por el artículo 1 de la UNCAT. Por ende, no puede sino concluirse que la obligación de tipificación contemplada por el artículo 4 de la UNCAT se encontraría incumplida.

b.2) Adecuación del tipo interno a la CIPST

A diferencia de la UNCAT, en el caso de la CIPST no existen pronunciamientos de la Comisión o de la Corte IDH que den cuenta del grado de adecuación de los artículos 150 A y B del Código Penal a los artículos 2 y 3 de la CIPST. A pesar de ello, es posible constatar varias diferencias entre el tipo interno y la definición de la referida convención regional:

- A diferencia del artículo 150 A del Código Penal, el artículo 2 de la CIPST no limita las potenciales víctimas a aquellas personas que se encuentren privadas de libertad.

- El artículo 150 A del Código Penal no abarcaría aquellos actos que consistan en "la aplicación sobre una persona de métodos tendientes a anular la personalidad de la víctima o a disminuir su capacidad física o mental, aunque no causen dolor físico o angustia psíquica", reconocidos por el artículo 2 de la CIPST.

- A diferencia de la CIPST que utiliza el vocablo tortura, el artículo 150 A emplea la expresión "tormentos o apremios ilegítimos".

- El artículo 150 A no exige -como señalamos antes- un propósito específico, mientras que el artículo 2 de la CIPST sí requiere una finalidad.

- El artículo 150 B del Código Penal, al encontrarse redactado en términos genéricos ("participare en la comisión"), parecería cubrir una mayor cantidad de

46 Por ejemplo, mientras este trabajo está siendo finalizado, se ha hecho público un video que data del año 2013, en el que se aprecia a funcionarios de Gendarmería golpeando severa y repetidamente a un grupo numeroso de internos luego de un intento frustrado de fuga por parte de dos personas, en un establecimiento penitenciario ubicado en Rancagua. El Gobierno y el INDH calificaron como tortura dichos actos. Véase "El Gobierno e INDH califican de inaceptables las 'torturas' en cárcel de Rancagua". La Nación, 21 de agosto de 2014. Disponible en: <http://www.lanacion.cl/noticias/pais/ddhh/gobierno-e-indh-califican-de-inaceptableslas-torturas-en-carcel-de-rancagua/2014-08-21/142537.html> [consulta: 21 de agosto de 2014]. 
formas de responsabilidad de personas privadas que el artículo 3 letra b) de la CIPST (por ejemplo, el encubrimiento) ${ }^{47}$.

De las diferencias recién señaladas, las dos últimas no deben ser consideradas negativamente, pues permiten que el tipo interno de tortura abarque casos que no quedarían comprendidos en la definición de la CIPST. Las consideraciones relativas a la denominación del ilícito hechas presentes al momento de analizar la adecuación del tipo interno a la UNCAT, también resultan aplicables para el caso de la CIPST. Respecto a las otras diferencias, ellas implican que la consagración normativa interna de la tortura abarque menos casos que la de la CIPST. Por lo tanto, al igual que con la UNCAT, Chile estaría en una situación de incumplimiento de la obligación de tipificación derivada de la CIPST.

\section{El cumplimiento de la obligación de tipificación del delito de tortura}

Si como constatamos, los artículos 150 A y B del Código Penal no se adecúan en su totalidad a las definiciones entregadas por la UNCAT y por la CIPST, entonces es forzoso concluir que el Estado chileno se encuentra incumpliendo las obligaciones de tipificación derivada de los referidos tratados. Por ende, el Estado debe adecuar su legislación a las definiciones de la UNCAT y la CIPST a través de una reforma.

En principio, cualquier iniciativa legal que busque adecuar el tipo interno del delito de tortura a los estándares internacionales debiera ser bien recibida. Por ejemplo, tres proyectos de ley presentados entre 2009 y el presente año ${ }^{48}$ tienen por objetivo adecuar el delito de tortura contemplado en el Código Penal a la UNCAT. Con todo, cabe prevenir que no cualquier iniciativa que tenga por orientación la adecuación de la normativa interna a estándares internacionales será apta para satisfacer íntegramente las obligaciones de tipificación de la tortura.

La razón para adoptar una actitud minuciosa frente al tipo de iniciativas legales referidas, es que Chile ha ratificado dos tratados (la UNCAT y la CIPST), emanando de

47 La existencia de esta diferencia depende de la interpretación que se haga del artículo 3 letra b) de la CIPST, toda vez que si por ejemplo se interpreta extensamente la expresión "cómplice", el encubrimiento podría quedar cubierto por ella.

48 Boletín No 6691-07, que modifica el Código Penal en lo relativo al delito de tortura, adecuándolo a la Convención Contra la Tortura y otros Tratos o Penas Crueles, Inhumanas o Degradantes; Boletín No 670207 que tipifica el delito de tortura; y Boletín No 9589-17 que modifica el Código Penal, en lo tocante a la tipificación del delito de tortura. Disponibles en http://www.camara.cl. 
cada uno de ellos una obligación de tipificar la tortura como delito autónomo, en virtud de la cual el tipo interno debe abarcar a lo menos los elementos de las definiciones contempladas por cada uno de esos tratados. Luego, como las definiciones de tortura de los tratados en comento no son iguales, se genera la posibilidad de que una de esas definiciones sea más amplia. En consecuencia, se hace necesario explorar las diferencias que existen entre las definiciones establecidas por la UNCAT y la CIPST $^{49}$ :

- La CIPST no exige, a diferencia de la UNCAT, que los dolores, penas o sufrimientos sean graves.

- La CIPST considera como tortura "la aplicación sobre una persona de métodos tendientes a anular la personalidad de la víctima o a disminuir su capacidad física o mental". En la UNCAT, la aplicación de los métodos descritos por la CIPST no está explícitamente comprendida. Además, en la CIPST no es necesaria la existencia de dolores como consecuencia de la aplicación de los métodos señalados, mientras que en la UNCAT necesariamente deben existir dolores o sufrimientos graves físicos o mentales.

- Tanto en la CIPST como en la UNCAT, es enunciativo el listado de propósitos en los que pueden fundarse los actos constitutivos de tortura. Empero, en la CIPST la lista es más enunciativa que en la UNCAT. En efecto, mientras que la CIPST admite "cualquier otro fin", la UNCAT exige que la razón esté basada en cualquier tipo de discriminación, de tal manera que en este último tratado no cualquier fin encaja en la definición.

- Ambas convenciones contemplan en sus definiciones la posibilidad de que en el acto constitutivo de tortura puedan participar sujetos privados, vinculados al hecho (acción u omisión) de un funcionario público. Empero, la CIPST vincularía a los privados en una forma más categórica al regular formas específicas de participación en su artículo 3 letra b) (ordenar, instigar o cometer o inducir a la comisión, ser cómplices), mientras que en la UNCAT la posibilidad de participación de privados se deduce de la formula "a instigación suya [del funcionario público o una persona en ejercicio de funciones públicas], o con su consentimiento o aquiescencia”, sin que se regulen formas específicas de participación.

- Por último, en la definición de la UNCAT no sólo puede ser sujeto activo un

49 NASH, C. «Alcance del concepto de tortura y otros tratos crueles, inhumanos y degradantes» [en línea]. Anuario de Derecho Constitucional Latinoamericano, año XV, 2009 p. 594. Disponible en: <http://www. juridicas.unam.mx/publica/librev/rev/dconstla/cont/2009/pr/pr34.pdf> [consulta: 9 de agosto de 2014]. En el mismo sentido, BuENo, G. «El concepto de tortura y de otros tratos crueles, inhumanos o degradantes en el derecho internacional de los derechos humanos». Nueva Doctrina Penal, 2003/B, pp. 618-619. Debe prevenirse que sólo las primeras cuatro diferencias son indicadas por los referidos autores. 
funcionario público, sino también una persona en ejercicio de funciones públicas, mientras que la CIPST considera sujeto activo a los empleados o funcionarios públicos que actúen en ese carácter. Por ende, la CIPST no consideraría como sujeto activo a personas en el ejercicio de funciones públicas.

En consideración de las diferencias señaladas, resulta claro que -salvo por no contemplar la hipótesis de la persona en ejercicio de funciones públicas como sujeto activo-, la CIPST contiene una definición de tortura más amplia que la establecida en la UNCAT.

Teniendo en cuenta lo anterior, una iniciativa legal que adecúe el tipo penal interno de la tortura a la UNCAT (como se pretende con los boletines No 6691-07, 6702-07 y 9589-17) satisfaría la obligación de tipificación emanada de dicho tratado, pero no necesariamente la que emana de la CIPST, por cuanto la definición de tortura de esta última es en general más amplia que la de la UNCAT. Por lo tanto, resulta fundamental que al momento de diseñarse iniciativas legales que pretendan adecuar la definición de tortura a los estándares internacionales, se dimensionen correctamente los alcances del tipo interno de manera tal que puedan cumplirse las obligaciones de tipificación de la UNCAT y la CIPST. Al contrario, si no se adopta en el ámbito legislativo una actitud suficientemente diligente en relación a esta materia, no existe seguridad alguna de que el Estado chileno pueda abandonar la situación de incumplimiento en la que se encuentra, y por ende la posibilidad de declararse la responsabilidad internacional del mismo podría permanecer viva. En efecto, si por ejemplo llegasen a ser aprobadas iniciativas legales como los boletines No 6691-07, 6702-07 y 9589-17 -que sólo pretenden satisfacer los estándares impuestos por la UNCAT pero no los de la CIPST-, nada obstaría a que eventualmente el Estado chileno pudiera ser declarado responsable, por la Corte IDH, de violaciones a los artículos 1 y 6 de la CIPST por no abarcar el tipo interno de tortura todos los supuestos a los que se extienden los artículos 2 y 3 de dicho tratado ${ }^{50}$.

En definitiva, ante un escenario configurado por la existencia de obligaciones jurídicas de tipificación incumplidas, sería preferible que el Estado chileno adopte una definición interna del delito de tortura que contenga a lo menos los elementos indicados por la definición contemplada por el artículo 2 y 3 de la CIPST, sumando la hipótesis consagrada en la UNCAT del funcionario en ejercicio de funciones públicas como sujeto activo ${ }^{51}$. Esta última alternativa, de hecho, no resulta contraria a las disposiciones de la UNCAT, toda vez que -como se indicó anteriormente- su artículo 1.2 permite

50 Como ocurrió en los casos "Heliodoro Portugal vs. Panamá" y "Goiburú y otros vs. Paraguay", mencionados supra.

51 Insistimos en que esta posibilidad se presenta como preferible, teniendo en cuenta exclusivamente la existencia de obligaciones incumplidas que pudieran dar lugar a la responsabilidad del Estado. Por lo tanto, no se consideraron otros factores para llegar a esa conclusión, como la calidad técnica de las definiciones de los tratados y las críticas que se han formulado a ellas. 
la existencia de normas nacionales o internacionales que consagren una definición más amplia de la tortura.

Estimamos que la adecuación de la normativa interna a los estándares internacionales sobre tipificación del delito autónomo de tortura debe realizarse a través de una reforma al Código Penal. Específicamente, los actuales artículos 150 A y 150 B deben ser reemplazados por disposiciones que -como señalamos anteriormente- contemplen los elementos de la CIPST, junto a la posibilidad de participación de personas en ejercicio de funciones públicas reconocidas en la $\mathrm{UNCAT}^{52}$. Con todo, creemos que la referida adecuación no debiera comportar una reproducción literal de los artículos 2 y 3 de la CIPST. Si bien la transcripción de tales preceptos evitaría el riesgo de incumplir las obligaciones de tipificación, la utilización de esta técnica legislativa podría afectar la operatividad de la norma interna debido a las diferencias que podrían existir entre los términos y expresiones empleados en el instrumento internacional, y aquellos términos y expresiones que son usuales en el sistema normativo nacional ${ }^{53}$. Lo que debe perseguirse es que entre los preceptos internos que establezcan una nueva tipificación del delito de tortura y las disposiciones relevantes de los tratados antedichos, exista una congruencia desde un punto de vista semántico.

\section{Conclusiones}

Debe matizarse la afirmación realizada por el Ministro de Justicia en cuanto a que existirían compromisos incumplidos respecto al ordenamiento internacional sobre la tortura al no encontrarse esta tipificada penalmente. En efecto, no puede afirmarse con total seguridad que el delito de tortura no esté tipificado en el ordenamiento jurídico interno, toda vez que el delito de "tormentos o apremios ilegítimos" cumpliría dicho rol. No obstante, no puede negarse que en materia de tortura existen compromisos pendientes incumplidos. A este respecto, Chile está obligado por la UNCAT y la CIPST a consagrar y sancionar en su legislación penal todos aquellos actos que sean constitutivos de tortura de acuerdo a las definiciones brindadas por dichas convenciones, las que representan un estándar mínimo. Si bien los artículos 150 A y B del Código Penal fueron agregados por la ley No 19.567 con la intención de tipificar la tortura, tales disposiciones, por las razones que han sido expuestas, no logran abarcar todos los elementos de las definiciones de la UNCAT y la CIPST. Es por lo anterior que el Estado se encuentra

52 El supuesto de "persona en el ejercicio de funciones públicas" quedaría cubierto por la definición (para efectos penales) del concepto de funcionario público consagrada por el artículo 260 del Código Penal.

53 Véanse BASCUNÁAN, A., op. cit. y, del mismo autor, «El Derecho Penal chileno ante el Estatuto de Roma». Revista de Estudios de la Justicia, no 4, 2004, pp. 116-117. 
incumpliendo las obligaciones de tipificación de ambos tratados, situación que podría dar lugar a que se declare la responsabilidad del mismo en una instancia internacional. Por lo tanto, la consagración de un tipo interno que cumpla los estándares internacionales es una tarea urgente. Con todo, es necesario que el tipo que se incorpore satisfaga las exigencias tanto de la UNCAT como de la CIPST, siendo deseable que el tipo interno -considerando la mayor amplitud de la definición de la CIPST- abarque a lo menos los elementos de la definición de la segunda, integrando el supuesto de la persona en ejercicio de funciones públicas. Sólo así el Estado dará cumplimiento a la obligación de tipificación de ambos tratados. 
6 - Gonzalez.indd 90 